\title{
ASYMMETRICAL ASSIMILATION OF ATLAS VERTEBRA
}

Vandana $\mathrm{R}^{1}$. Ravikumar ${ }^{2}$.

1. Assistant Professor, Department of Anatomy, Navodaya Medical College, Raichur. Karnataka.

2. Associate Professor, Department of Otorhinolaryngology \& Head \& Neck Surgery, Raichur Institute of Medical Sciences, Raichur. Karnataka.

\section{CORRESPONDING AUTHOR:}

Dr. Vandana R.,

Assistant Professor, Department of Anatomy,

Navodaya medical college, Mantralayam road,

Raichur, Karnataka.

E-mail: drvandanar@gmail.com

\section{HOW TO CITE THIS ARTICLE:}

Vandana R, Ravikumar. "Asymmetrical Assimilation of Atlas Vertebra". Journal of Evolution of Medical and Dental Sciences 2013; Vol2, Issue 23, June 10; Page: 4102-4110.

BACKGROUND: Assimilation is congenital fusion of atlas vertebra with the base of occipital bone; it may be partial or complete fusion. It is the most common anomaly found at the cranio-vertebral junction. This anomaly results due to failure in segmentation and separation of lower occipital sclerotome and $1^{\text {st }}$ cervical sclerotome during development of fetus. MATERIAL METHODS: study was conducted on 30 dry skull bone collected from department of our college and observed for the assimilation of atlas vertebra. RESULTS: Assimilation of atlas vertebra was observed in 2 skull bones and details of these are described in following article. CONCLUSION: The knowledge of this osseous anomaly is important for neurosurgeons, orthopedician, anesthetists and radiologists.

KEY WORDS: assimilation, atlas, foramen magnum,

INTRODUCTION: Atlas is the first cervical vertebra, it is ring shaped, without a body. It has an anterior arch, a posterior arch and two lateral masses. The lateral masses articulate with the occipital condyles to form ellipsoid type of synovial joints. The anterior arch articulates with the dens of the axis vertebra to form a pivot type of synovial joint. The posterior arch is grooved by the third part of the vertebral artery [1].

There are various anatomical abnormalities and variants in the region of the atlanto-occipital junction. The assimilation of atlas appears to be the most common in this region. Congenital bony fusion of the atlas vertebra to the base of the occipital bone of the skull is described as assimilation of the atlas. It is also known as occipito-cervical synostosis, occipitalisation of atlas and atlanto-occipital fusion.

The disorder results from faulty development between the occiput and the adjacent vertebra during the early embryonic weeks. During this early embryologic development, the first-throughfourth somites unite to form a basi-occiput. The caudal regions of the fourth somite, undergoes fusion with the cranial half of the first somite. Other malformations may commonly occur with cranio-cervical fusion. They are:

1. Pseudo or true basilar impression 


\section{ORIGINAL ARTICLE}

2. Absence or malformation of the transverse ligament

3. Hyperplasia of the dens

4. Aplasia of the dens and

5. Anomalies of the vertebral artery due to the absence or malformation of the foramen transversarium. [2]

Motabagani and Surendra (2006) quoted in their paper that, it was first described by Rokitansky in 1844 and Schuller in 1911 who demonstrated this anomaly on roentgen graphically. Assimilation of the atlas may be partial or complete. Multiple variations of partial assimilation have been reported and may involve any aspect of atlanto-occipital articulation. The prevalence ranges from 0.08-3 percent of the general population. Total or partial assimilation of the atlas may be noted with the latter being the most common [3]. Ranade et al (2007) have examined 98 Indian human skulls for assimilation of atlas and noted two cases showing various degree of assimilation of atlas [4]. Sani et al (2009) have also observed assimilation of atlas in 2 Indian skulls [5].

MATERIAL AND METHODS: The present study was conducted on 30 skull bones in department of Anatomy of our college and observed for assimilation of atlas vertebrae with basilar part occipital bone. Among 30 skull bones we found 2(two) skull bones with partial and asymmetrical assimilation of atlas vertebra.

RESULTS: The following observations were noted, IN SKULL A:

1. The assimilation is not exactly in the midline but slightly inclined to the right side.

2. Left lateral mass was slightly protruding into foramen magnum (FM) reducing its dimensions. Sagittal diameter was $27 \mathrm{~mm}$ and transverse diameter was $15 \mathrm{~mm}$ in posterior aspect.(fig no.1)

3. Superior articular facets of atlas have completely fused with condylar facets of occipital bone

4. Anterior arch of atlas is partially fused with anterior margin of foramen magnum leaving a gap between it basilar part of occipital bone. (fig no.2)

5. Spina bifida posterior of atlas vertebra, means each half of posterior arch of atlas have not fused with each other and projecting from lateral masses.(fig no.3)

6. Right hypoglossal foramen is reduced in size (fig no.4C)

7. Right foramen transversarium is not complete, deficient anterolaterally. (fig no.4A)

8. Right foramen transversarium is fused with jugular process of occipital bone. (fig no.4B)

9. There is a deep groove anterolateral to right lateral mass of atlas and the right jugular foramen is directed forwards and medially. The same groove contains the opening of hypoglossal canal which is much reduced in diameter.(fig no 6B)

10. Left hypoglossal foramen is larger in diameter.(fig no $5 \mathrm{~A}$ )

11. Left foramen transversarium is complete and it not fused with jugular process of occipital bone.(fig no 5B)

12. Inferior articular facet of atlas on the left side is larger when compared to the right facet. .(fig no 6A) 


\section{ORIGINAL ARTICLE}

\section{IN SKULL B:}

1. Assimilation is not in the midline slightly inclined to left side

2. Incomplete fusion of anterior arch of atlas with basilar part of occipital bone is forming a foramen which is situated to the left of midline(fig- 7)

3. Spina bifida posterior of atlas vertebra, where each half of posterior arch has not fused with each other.(fig-8)

4. Right half of posterior arch of atlas is fused with posterior margin of FM (fig-9)

5. Left half of posterior arch has not fused with posterior margin of FM (fig-9)

6. Tip of left transverse process is very close to tympanic plate of temporal bone leaving no gap between the two.(fig-10)

7. Right inferior articular facet of atlas is slightly protruding into FM

8. It is also observed that all the foramen at the base of skull were larger on the right side when compared to left side.

9. Left mastoid process was longer than right side.

10. Other features as observed on gross examination were appeared to be asymmetrical.

DISCUSSION: Assimilation of atlas is one of the most common congenital osseous malformations of craniovertebral junctions. This anomaly exists in one per 109 adult human skulls of Asian origin. The right lateral mass of atlas has been protruding into foramen magnum narrowing its anterior part and also uneven in shape. This may be because; assimilation may involve any aspect of atlanto-occipital articulation [2]. In our skull bone there was slight protrusion into FM.

Jayanti et al. (2003) have reported two cases of occipitalization with spina bifida of atlas. In the first case there was a complete fusion of only one of the transverse process with occipital bone, and an incomplete fusion of anterior arch of atlas. In the second case the anterior arch of the atlas has fused with occipital bone [6]. Nayak S et al. (2005) also reported about the fusion of the atlas vertebra with the occipital bone. In this report, the two superior facets on the lateral mass had completely fused with the occipital condyles. The anterior arch had an incomplete fusion with the basilar part. The posterior arch was also incomplete. It was represented by two small projections from the two lateral masses [7]. In our study the skull bone A showed all features similar to the cases reported by Jayanthi et al \& Nayak S.

The assimilation may reduce the foramen magnum and lead to neurological complication due to compression of the spinal cord [4]. In our study in both the skull bones there was slight protrusion into foramen magnum and transverse diameter has appeared to be much reduced in skull A, therefore we presume that clinical symptoms associated with the spinal cord compression could be a cause of death in that case. Although the assimilation is a congenital condition, many patients do not develop symptoms until the second decade of life. This may be due to a gradual increasing degree of ligamentous laxity and instability with aging. The onset of clinical symptoms can be sudden and precipitated by minor trauma, but death has also been reported [8].

Even though the assimilation of atlas is the most common anomaly found in cranio-cervical junction, head and neck surgeons should be aware that such an anomaly may exist without any typical symptoms. Restriction or absence of movement in this articulation may be the first sign which attract the attention of surgeons regarding assimilation. The knowledge of assimilation may be of importance to orthopedic surgeons. It may be the cause of failure of cisternal puncture so may be 
of importance for anesthetist. Physiotherapist dealing with the neck pain and radiologist dealing with abnormalities of cervical spine must also be aware of this condition [2]. Transverse process is very important landmark for head and neck surgeons, when it is inclined and fused to occipital bone, there may be confusion in reaching various structures and also this led to asymmetry in structure and shape of apertures for the vessels and nerves around the foramen magum [9]. In the present study, the transverse process of skull B is almost attached to the Styloid process which may cause compression of important neurovascular structure around it.

According to McRae \& Barnon (1953), patients with occipitalization of the atlas may have the following physical features like low hairline, torticollis, restricted neck movements and / or abnormal short neck. In neurological examination of the atlanto occipital fusion, patient may reveal the following clinical findings: headache, neck pain, numbness and pain in the limbs, weakness, abnormal head posture, posteriorly located dull aching headache. Cranial nerve findings associated with occipitalization of the atlas include tinnitus, visual disturbances and lower cranial nerve palsies leading to dysphagia and dysarthria. The neurological symptoms and signs of atlanto-occipital fusion cannot be distinguished from those of the Arnold Chiari malformation as the pathophysiology of both is essentially the same [10]. Assimilation may also result in compression of vertebral artery or even its total occlusion in bony canal, leading to dizziness, seizures and syncope [5].

CONCLUSION: Assimilation of atlas is a common congenital anomaly in the cranio-vertebral region; therefore the skilled clinician should be aware of atlanto -occipital fusion which may exist without any typical symptomological presentation. The serious consequence of upper cervical manipulation with this type of osseous anomaly reflects the importance and need for a thorough clinical assessment and evaluation, on every patient.

\section{REFERENCES:}

1. Johnson D, Ellis H, Collins P, Standring S, editor. Gray's anatomy: the anatomical basis of clinical practice.39th ed. 90 Touttenham court road London W1T 4LP: Elsevier Churchill Livingstone; 2005.

2. Grilliot JR, Oswal CA. Assimilation of the atlas and occiput: a case report. The journal of the CCA. 1988; Vol 32(4): 195-198.

3. Surekha Jadhav, Manoj Ambali, Raosaheb Patil, Megha Doshi, Priya Roy. Assimilation of tlas in Indian dry skulls. JKIMSU. 2012; Vol 1: 102-106.

4. Ranade AV, Rai R, Prabhu LV, Kumaran M, Pai MM. Atlas assimilation: A case report.Neuroanatomy 2007; 6: 32-33.

5. Sani V, Singh R, Bandopadhyay M, Tripathi S, Shamal S. Occipitalization of the atlas: its occurrence and embryological basis. IJAV 2009; 2: 65-68.

6. Jayanti V, Kulkarni R, Kulkarni R N. Atlanto- Occipital fusion. Report of two cases. J Anat. Soc. India. 2003; 52 (1): 71-73.

7. Satheesha Nayak .Asymmetric Atlas Assimilation and Potential Danger to the Brainstem: A Case Report. The InternetJournal of Biological Anthropology. 2008; Volume 1 Number 2.

8. Hensinger RN. Osseous anomalies of the craniovertibral junction. Spine 1986; 11:323-333. 


\section{ORIGINAL ARTICLE}

9. Rajani Sangeetha J, Suttarwala IM, Rajani Jitendra K. An unusual case of unilateral atlantooccipital assimilation with skull asymmetry. National journal of medical research2012;2(2):238-240.

10. Mc, Rae, D.L.; Barnon, A.S. (1953): Occipitalization of atlas. American Journal of Roentgenology 70: 23 - 45.

\section{SKULL BONE A}

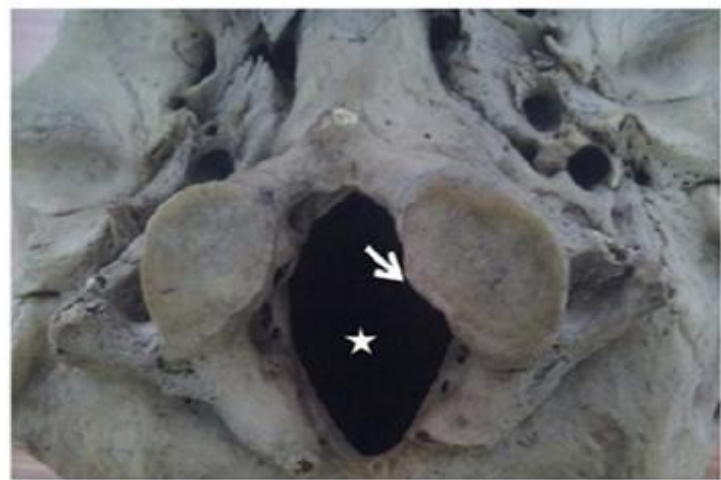

fig-1 showing protrusion of left lateral mass into foramen magnum

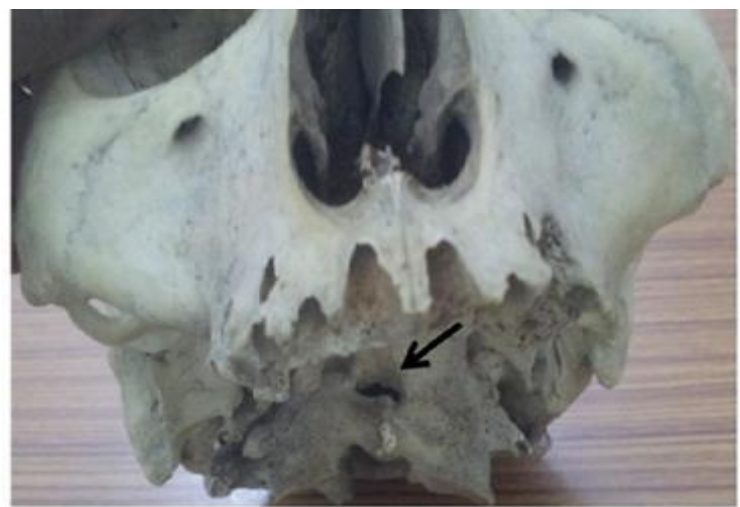

fig-2, showing foramen due to incomplete fusion of anterior arch with basilar part of occipital bone

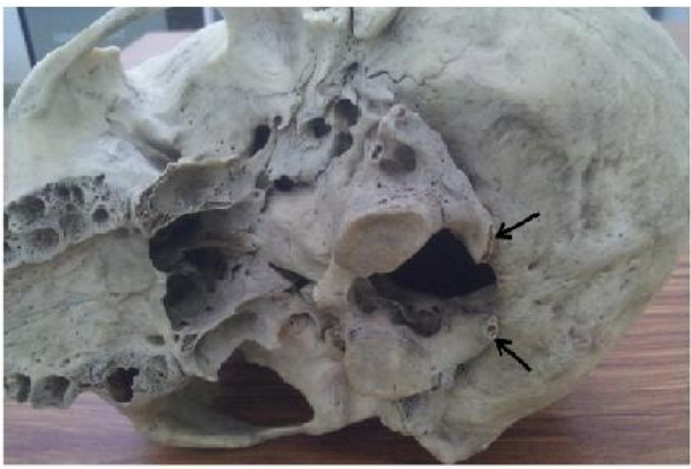

fig-3, showing spina bifida posterior of atlas,posterior arches projecting from lateral masses which are fused with posterior rim of foramen magnum 


\section{ORIGINAL ARTICLE}
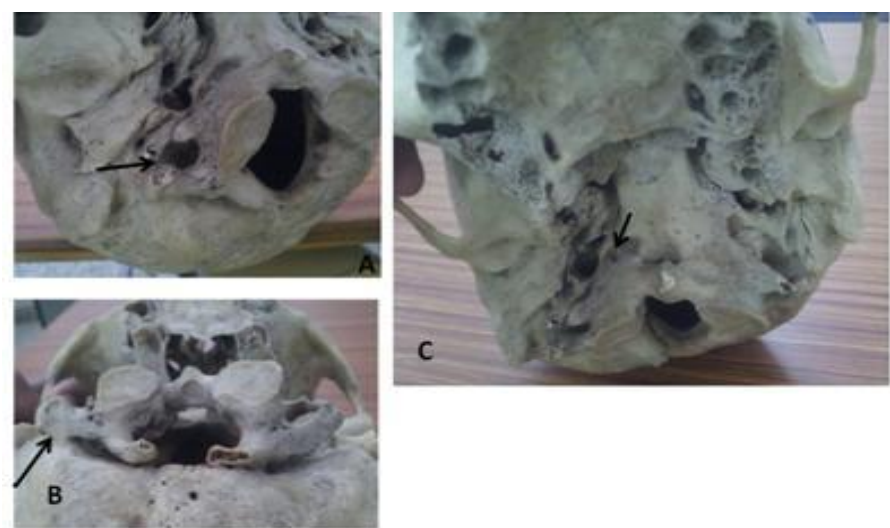

fig-4,A- incomplete right foramen transversarium, Bfusion of right foramen transversarium with right jugular process.C-smaller right hypoglossal canal

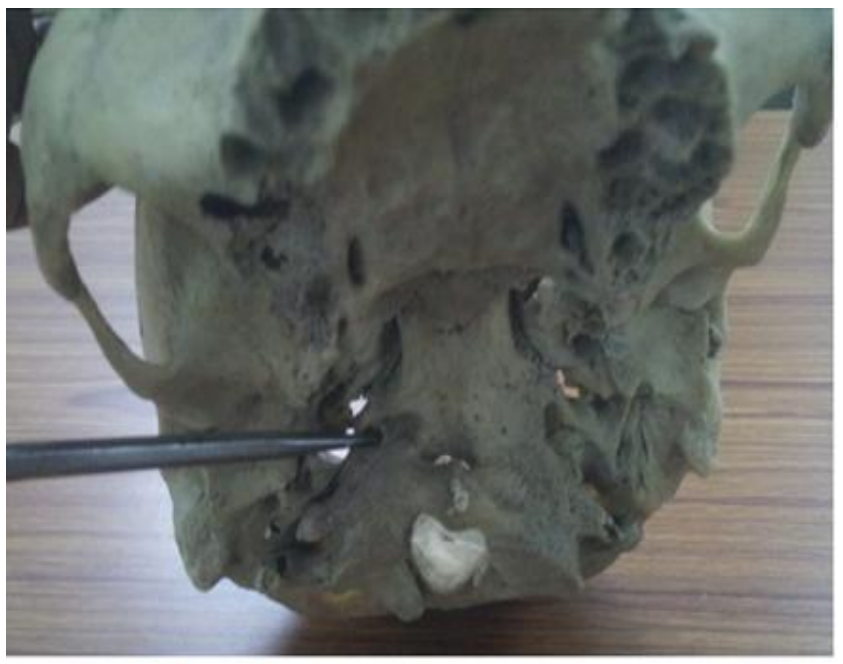

fig-4c smaller right hypoglossal canal 


\section{ORIGINAL ARTICLE}
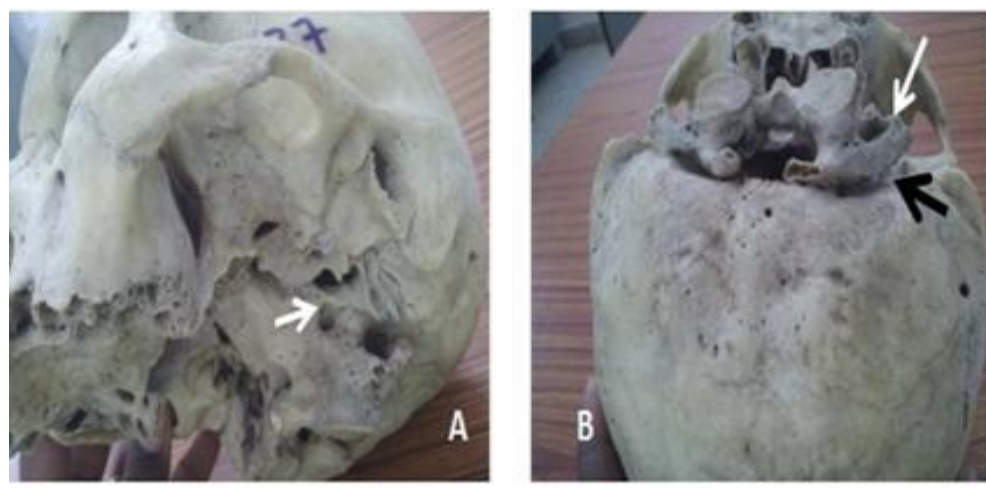

fig-5,A-larger left hypoglossal canal, B-complete left foramen transversarium(white arrow)and it has not fused with jugular process(black arrow)

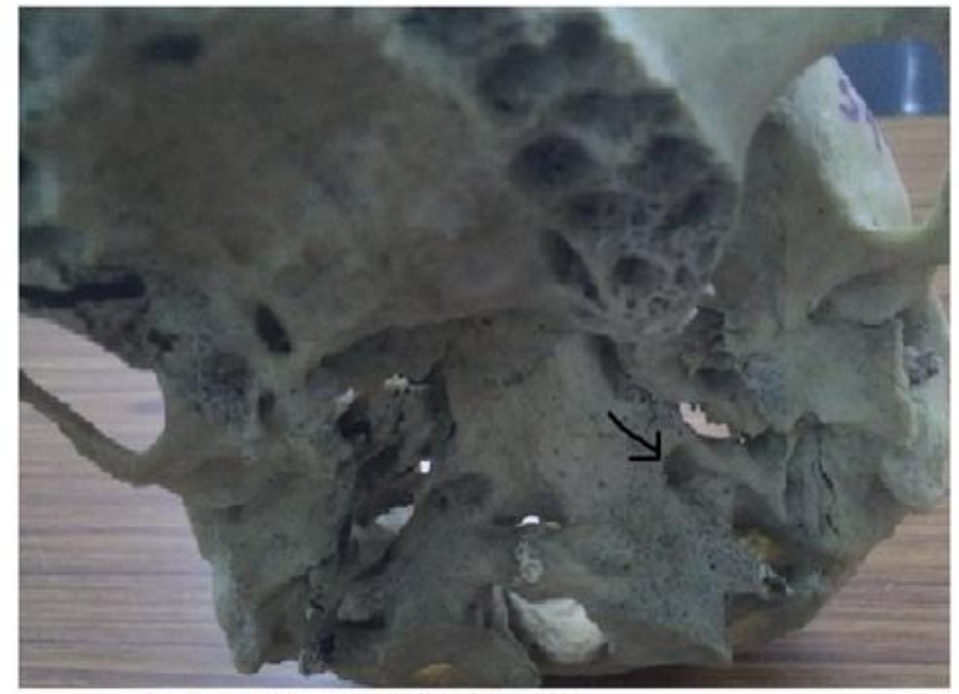

fig- 5A larger left hypoglossal canal
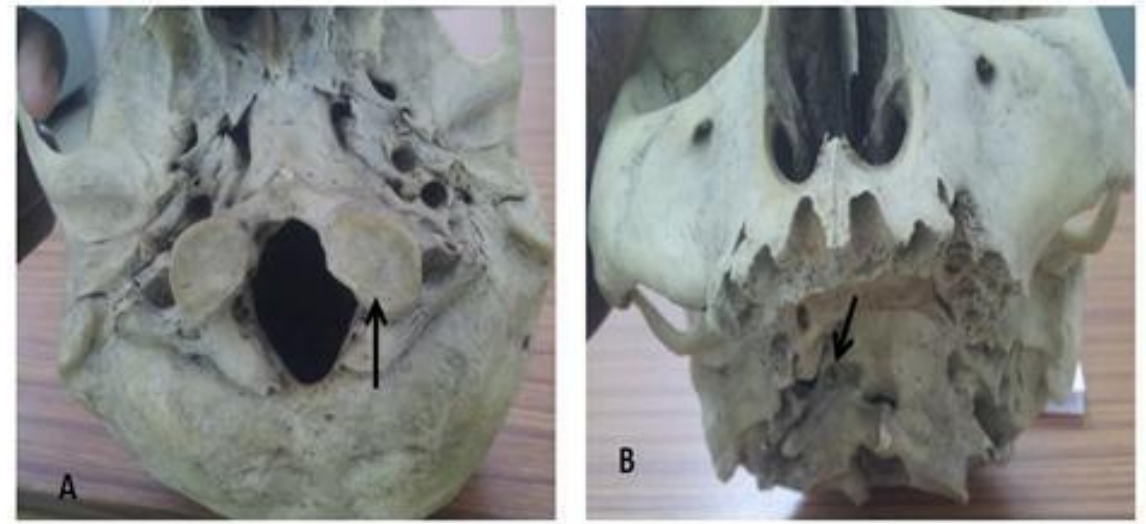

fig-6,showing larger left inferior articular facet, B-showing deep groove anterolateral to right lateral mass 


\section{ORIGINAL ARTICLE}

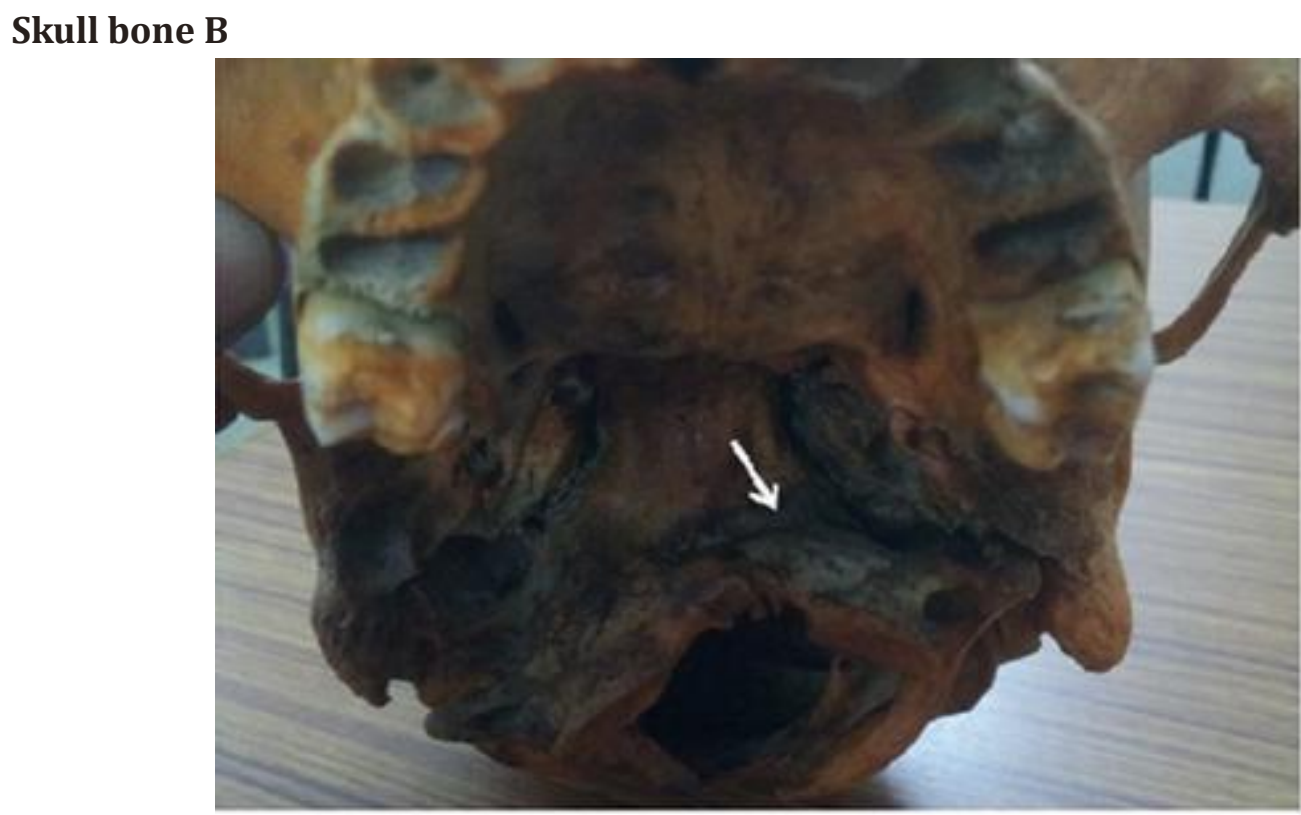

fig-7 incomplete fusion of anterior arch of atlas forming foramen between it and basilar part of occipital bone

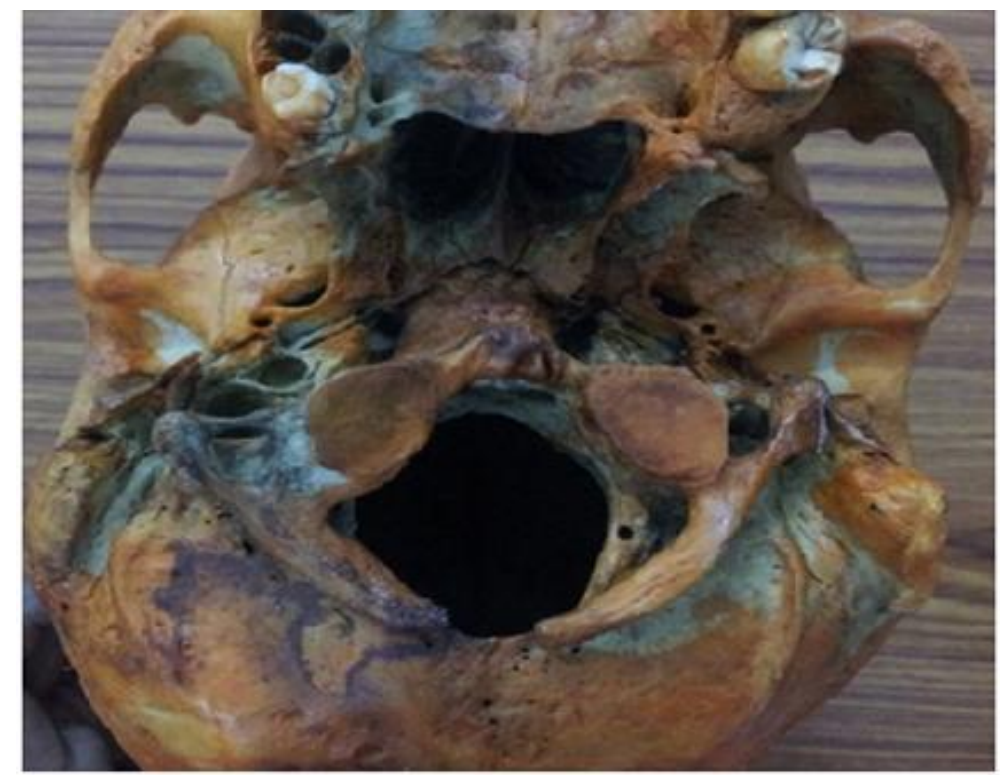

fig-8, spina bifida posterior, non fusion of each half of posterior arch of atlas 


\section{ORIGINAL ARTICLE}

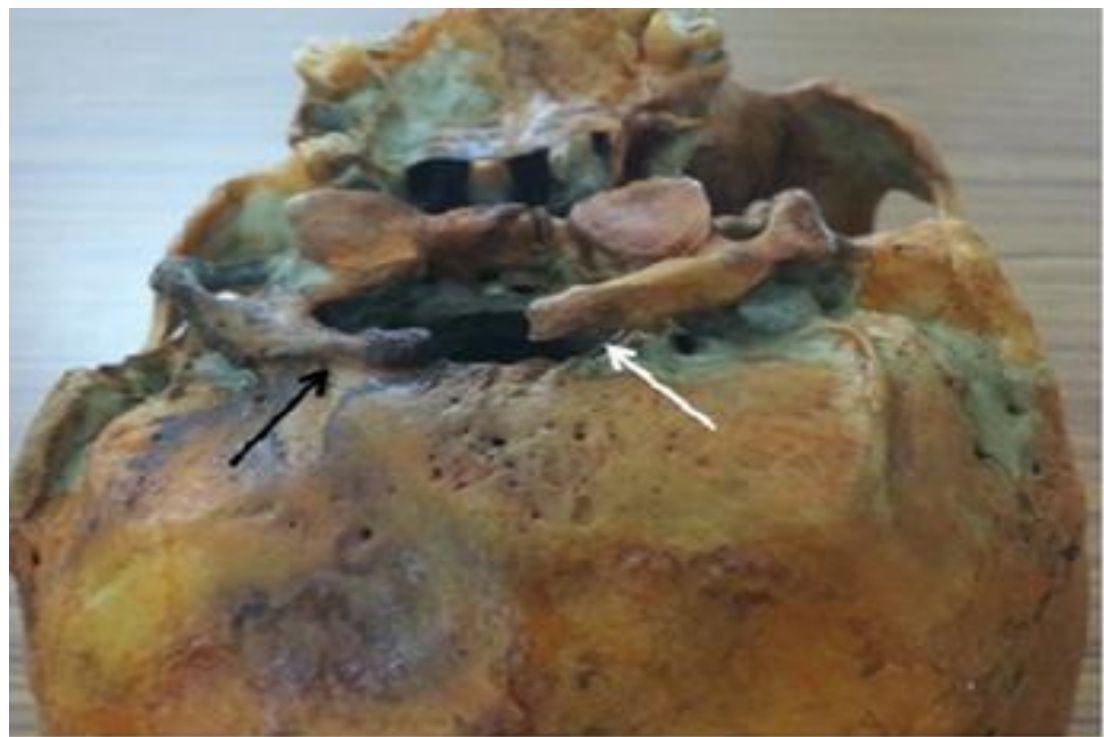

ig-9, black arrow- fusion of right half of posterior urch, white arrow- non fusion of left half of posterior rch of atlas with posterior rim of foramen magnum.

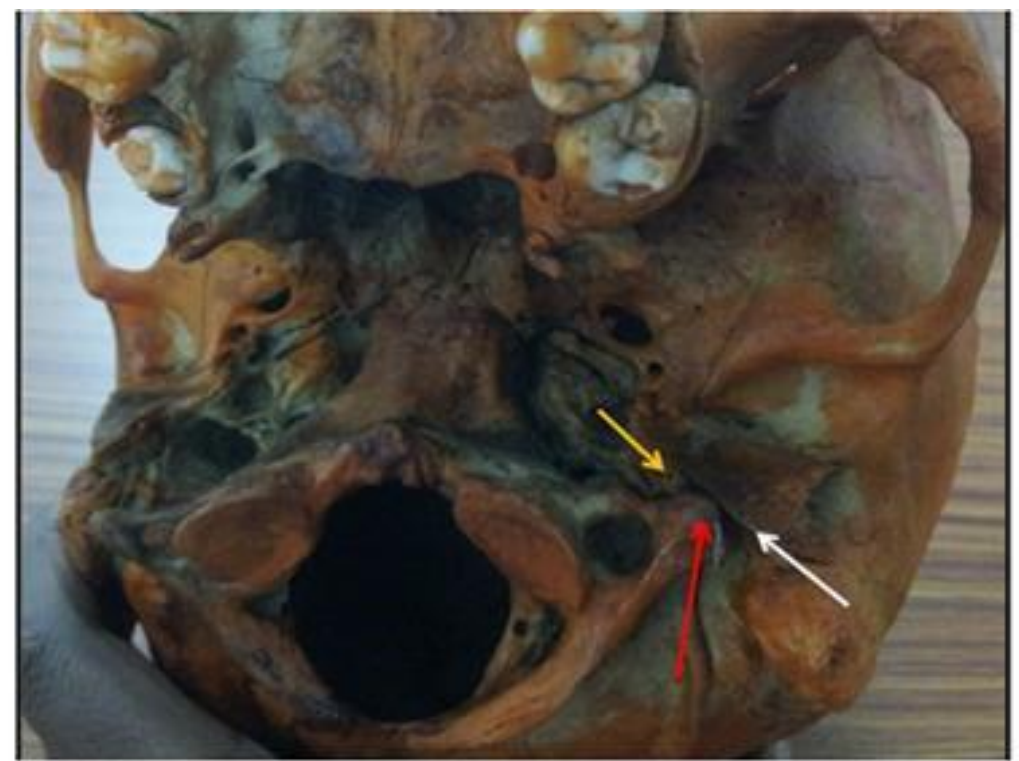

fig-10,showing relation of tip of left transverse process(red arrow ) with tympanic plate (white arrow) and styloid process(yellow arrow) 